but one aspect of a multitude of problems of health and welfare in old age, and dramatic improvement in the health of some old pcople a few weeks after admission to a residential home raises the question that their admission might have been avoided had they been better fed in their own homes; this would certainly seem to have advantages also in economic terms.

\title{
REFERENCES
}

Andrews, J., Brook, M. \& Allen, M. A. (1966). Geront. clin. 8, no. 5, p. 257 .

Durnin, J. V. G. A. (1964). In Current Achievements in Geriatrics. Vol. 5, p. 4I. [W. F. Anderson and B. Isaacs, editors.] London: Cassell.

Exton-Smith, A. N. \& Stanton, B. R. (I965). Report of an Investigation into the Dietary of Elderly People Living Alone. King Edward's Hospital Fund for I.ondon.

Griffiths, L. L., Brocklehurst, J. C., Scott, D. L., Marks, J. \& Blackley, J. (1967). Geront. clin. 9, no. I, p. I.

Ministry of Agriculture, Fisheries and Food: National Food Survey Committee. (1966). Damestic Food Consumption and Expenditure, 1964. London: H.M. Stationery Office.

Morris, G. K. (1959). Nutrition, Iond. 13, I25.

Read, A. E. A., Gough, K. R., Pardoe, J. L. \& Nicholas, A. (1965). Br. med. J. ii, 843 .

Townsend, P. \& Wedderburn, D. (1965). The Aged in the Welfare State (The Interim Report of a Survey of Persons aged $6_{5}$ and over in Britain, $x_{962}$ and 1963 ). London: Bell.

\section{Feeding the elderly in their own homes: meeting the need}

\author{
By R. C. M. Pearson, Medical Officer of Health, \\ City and County of Nercastle-upon-Tyne
}

\section{Housing}

It has been assumed that provision of the basic financial needs of the social isolates, the housebound and the mildly mentally disturbed, especially those of them who live alone and present the real nutritional problem, is beyond the scope of this paper. So many of them live in the twilight areas with poor cooking facilities, but when rehoused for medical reasons or owing to slum clearance, they need very careful consideration and skilled guidance so that they will have a relative, friend or sympathetic neighbour reasonably near at hand. No social service can ever hope to meet all their needs as they get older. There is a growing opinion that when given this type of 'housing management' this group makes less demands on residential care. As a result, adequate warmth at home leads to greater mobility and better appetite with all-round improvement in health and less demand on the other services.

Groups of outward-looking flatlets and bungalows in reasonable proximity to residential homes enable the frail elderly to have a midday meal in the dining room. The staff of the home with their own warden can together maintain a friendly eye on their total food intake. Transport may be necessary.

\section{The Home Help Service}

The greatest contribution to the prevention of malnutrition amongst the isolated elderly is the Home Melp Service, but this service is limited by finance and recruit- 
ment. In Newcastlc upon Tyne the average number of hours available per person is 4.9 per week, but this rarely permits all the shopping, cooking and domestic work to be undertaken, so the maintenance of these groups in their own homes is a severe strain, especially when 'their own' home help is ill or on holiday. These people cannot be left even for a brief period to fend for themselves. It is only possible in a population of 31200 over 65 in Newcastle upon Tyne to have a meal cooked by a home help for $\mathrm{I} \cdot \mathrm{I} \%$.

\section{Meals on wheels}

For the group who can potter about in their own homes, manage their own domestic work, but for one reason or another can neither shop nor cook, and decline an offer of transport to a day centre, meals-on-wheels maintain their nutritional level if provided often enough. Clearly some have more difficulty in cooking than others, so that an assessment of individual need is essential and the meals organizer cannot rely solely on 'recommendations' from such people as medical practitioners, health visitors and social workers alone as each one has a different standard.

It is important that those in greatest need of meals should have a daily service. Less than three or four times a week, unless relatives or neighbours help, does not maintain an adequate nutritional level. Too many elderly people are liable to split up the meal on delivery and reheat a portion later.

In Newcastle upon Tyne the service can provide a meal for: 77 once a week, I63 twice, I 32 three times, 49 four times, 31 five times, 20 six times and every day for 29; the total is some 1500 meals for 5 or persons.

In addition, the WRVS provide meals twice a week for $9^{8}$ persons.

Meals can be distributed from residential homes, a central kitchen or school canteen but only the first two can cover 7 days a week and school holidays. Dietetic considerations, as well as daily availability, point to the provision of a fully adequate service only from residential homes but expediency may dictate the use of all these sources and the careful planning of delivery rounds to meet individual needs.

Old people are fussy; they make pre-planning almost impossible; they change their views; they are not at home; they dictate times of delivery, but still they are so grateful and they rarely grumble at the is. $3 \mathrm{~d}$. charge.

Voluntary agencies and especially the WRVS (with their own transport and drivers) have a big contribution to make but in an urban area they can rarely provide a full service.

Day-to-day distribution is fraught with difficulties. Careful planning to save waste of food and journey time must allow for variations due to hospital admissions and discharges, deaths, holidays, etc., and is best associated with ambulance service planning and the use of specially designed vehicles with 'escorts' who can be employed also on other strictly transport duties such as escorting trainees, etc.

Some experimentation is required to provide and deliver more meals each day with the same equipment and transport but it takes considerable 'sales expertise' to persuade the elderly to accept what is not strictly a midday dinner.

Requests for assistance for elderly people come from many quarters but is there 
any evidence that any or all of these methods described are meeting the real needs of all who cannot maintain their own nutritional standards?

Nappy ( 1967), Chief Welfare Officer, City of Birmingham, uncovered a hitherto unknown need in Birmingham by postal circulation of the elderly with help from the Executive Council. Too much faith can be placed on registration of the elderly with frequent screening to pinpoint those likely to be in greatest need. It is wellnigh impossible to keep registers up to date and so an alternative alerting system is required. Regular visits by general practitioners and their 'associated' health visitors, nursing staff, social workers and voluntary visitors as well as regular (even daily) observation by wardens and caretakers of flats play a definite part but each elderly person needs a 'good neighbour' who has a telephone number which will alert the local authority services when an emergency arises.

Attempts at finding alternative methods of meal production (such as the use of prepacked frozen food and delivery in bulk) have proved either too expensive or too time-consuming. Some thought must be given to means of supplementing the vitamin $\mathrm{C}$ lost during transport of meals. Meals at lunchcon clubs cooked on the premises avoid this loss but meet other difficulties.

\section{Luncheon clubs}

The mobile elderly are not such a problem. They prefer luncheon clubs where both a hot meal and companionship can be found. Rather too many of these clubs open only on I or 2 days a week (fourteen and three respectively out of seventeen clubs providing 630 meals per week for the same population group) to make any real direct contribution to the nutritional state of the elderly but non-attendance of a regular member should be a means of alerting the social services if communications are sound.

\section{Communications}

General practitioners, health visitors and social workers know the times of special risk, such as immediately following bereavement, discharge from hospital (how important adequate warning is!), financial worry (real or imagined), etc. Holiday homes and convalescence and temporary care in a residential home help to tide over such periods but to succeed requires rapid communications and flexible services as well as well-trained, always available and devoted staff. No praise can be too high for those who weave their way through one of the most administratively complicated local authority and voluntary services.

Occasionally no-one alerts the service early enough and an elderly person is found to be in need of emergency admission to hospital or a residential home. Even more rarely Section 47 of the National Assistance Act 1948 has to be used. Whatever the circumstances a very careful medical assessment is required and is frequently best carried out in hospital. The underlying cause must be found and treated-it is not enough to rely on admission to a residential home and assume that good feeding will do the rest. To permit such a close working arrangement both geriatric and psychogeriatric consultant opinion should be immediately available to support the 
general practitioner and the local authority medical officer. An adequate number of beds in acute geriatric assessment units in hospital, as well as in local authority and voluntary residential homes, should be available to enable rapid interchange to take place.

Some thought has to be given to counting the cost of maintaining adequate nutritional standards for the elderly in their own homes by one or other of the means outlined above or by admitting them to a residential home. Individual factors are so variable that even if a cost limit were to be recommended assessment would be very difficult and vary from week to week. So, in the end, the personal wishes of the individual, if reasonable, are met whenever possible.

\section{REFERENCE}

Nappy, D. (1967). British Hospital fournal and Social Service Rerier,, p. 16r.

\section{Education of the general public}

By Elizabetil M. Davies, Department of Education and Science, Cardiff, and Winifred S. Hargreaves, Department of Education and Science, London

This paper is based on knowledge, acquired over 25 years, of work in schools, in teacher training establishments and in technical and further education colleges in England and Wales-on intimate knowledge of the work of voluntary organizations and the former Food Advice Service. The opinions expressed are personal and not necessarily those of the Department of Education and Science.

Even before the last World War there was some teaching of food values in schools -it was largely academic, the emphasis was mainly on deficiency diseases and available text books paid much attention to them. Some of these deficiency diseases were unknown in this country and others only slightly so, so little real benefit could be derived from the teaching. The most worthwhile attempt to get sound simple nutritional practices across was in the few Child Welfare Clinics then in existence to help mothers and children in the low-income groups. Dietitians, as now, were thin on the ground, their study had been largely scientific and the majority were employed in hospitals or on research. There were few opportunities for them to work in the social field, where good feeding habits under very limited incomes were difficult to achieve and where help and education were desperately needed.

The war came, the Government took over the control of foodstuffs and introduced rationing to secure an even distribution of food and to safeguard the needs of vulnerable groups. In 1940, the Ministry of Food formed a Food Advice Division in order to provide a nation-wide education service, charged with the task of getting across to the people, in the simplest terms, an understanding of how best to use available foods and how to meet the nutritional needs of their bodies.

The above-mentioned Service called upon the expertise of scientists, home 